\title{
Malaria in Pregnancy in Nigeria: A Literature Review
}

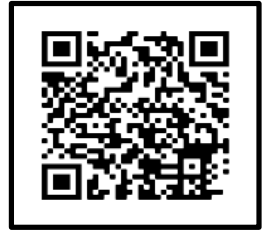

\section{JOSEPH OMANG*1, ANTOR O NDEP1, DOMINIC OFFIONGํ, FIDELIS OTU¹, KENNETH ONYEJOSE}

Malaria is caused by the parasite plasmodium which can be spread to humans through the bite of an infected mosquito. Of the five types of plasmodium (P. Falciparium, P.Ovale, P. Malaria, P. Vivax and P. Knowlesi), the plasmodium falciparium is the deadliest and affects the lives of almost 40 per cent of the world's population with pregnant women and children under-five years of age being the most affected. This mini-review involved the collation of findings from recent studies in regards to the prevalence of malaria infection among pregnant women and infants. A systematic analysis of recent literature on the prevalence of malaria in pregnancy from many authors was carried out and the facts synthesized to make an easy read. From the analysis of literature, Ten Thousand women and 200,000 babies were reported to be dying annually from complications of malaria in pregnancy which recorded a prevalence of 85 per cent in sub-Saharan Africa. More so, Fifty per cent of pregnant women were discovered to be carrying plasmodium falciparium in their placenta without even experiencing malaria signs/ symptoms, and this development was reported to have been responsible for Twenty per cent of stillbirths and 11 per cent of all maternal deaths. Malaria infection is considered a major threat to the lives and well-being of pregnant women and infants. Therefore, stakeholders should ensure that every clinical diagnosis of malaria in pregnancy is confirmed with a laboratory plasmodium falciparium-based diagnosis before the administration of antimalarial drugs. Furthermore there should be a stepping -up on the distribution of insecticide treated nets alongside enlightenment of pregnant women on ways of preventing mosquito bite. Instituting the aforementioned approaches is key to improving the health- seeking behaviour of pregnant women in particular and the wider population in general thus enabling them to stay malaria free throughout the period of pregnancy and infancy.

KEYWORDS: Malaria, Pregnancy, Plasmodium, Infant

\section{INTRODUCTION}

Malaria affects the lives of almost 40 per cent of the world's population, and the high risk group being pregnant women and young children (under 5-years of age) and about 10,000 women and 200,000 babies die annually because of malaria in pregnancy. Furthermore, 85 per cent of malaria cases in the world occur in subSaharan Africa, as there were 214 million malaria cases and 438,00o malaria deaths globally in 2015. Also, in sub-Saharan Africa 20 per cent of pregnant women attending ante natal clinic tested positive for the malaria parasite (Plasmodium Falciparum) as 72 per cent of pregnant women had at some point during their pregnancy suffered malaria infection, because 50 per cent of pregnant women carry the malaria parasite in the placenta without noticing it, which makes them three (3) times more likely to suffer from other severe diseases. ${ }^{1-3}$

\section{EFFECTS OF MALARIA IN PREGNANCY}

Malaria is responsible for 20 per cent of still births and 11 per cent of all maternal deaths by way of spontaneous abortion, maternal anaemia, placental pathologies, infant mortality and morbidity, intrauterine growth retardation and low birth weight. Other effects include: threatened abortion, miscarriage, premature delivery and low birth weight which all have serious public health implications for the mother, the fetus and newborn. 4,5

\section{MALARIA IN PREGNANCY: THE NIGERIAN EXPERIENCE}

In Nigeria, overall malaria prevalence stood at $79.5 \%$, in Lagos and Enugu States the prevalence during pregnancy was reported to be 52 and 99 per cent respectively, and having devastating effects on pregnant women, the fetus and the new born. ${ }^{6,7}$

\section{INCREASED RISK FOR MALARIA DURING PREGNANCY}

Mosquito (the vector that transmits the malaria parasite) has affinity for pregnant women because pregnancy causes women to release a greater than normal amount of Carbon Dioxide $\left(\mathrm{CO}_{2}\right)$ which adds to the odoriferous secretions during pregnancy, which

(C) Joseph Omang et al. This is an open access article distributed under the terms of the Creative Commons Attribution License CC-BY-NC 4.o, which permits unrestricted use, distribution and reproduction in any medium, provided the use is not commercial and the original author(s) and source are cited. 
attracts mosquitoes, coupled with the increased body surface and increased blood flow in the skin, exposing the pregnant woman to mosquito bite. Also, the accumulation of parasitized red blood cells in the placental vessels triggers an inflammatory process which has been known to cause an immune activation in the placental tissue which would not have occurred in a non-pregnant woman. ${ }^{1,4,8,9}$

\section{LABORATORY DIAGNOSIS: THE KEY TO PROPER CASE MANAGEMENT}

Clinical diagnosis is not a reliable malaria diagnostic technique especially in sub-Saharan Africa due to inadequate local epidemiological data on malaria and the presence of other febrile ailments which have similar signs and symptoms with malaria. Therefore all suspected malaria cases (clinical diagnosis) should be confirmed with a laboratory test as a concurrence World Health Organization's policy that all clinical diagnosis must be confirmed by a laboratory parasitebased diagnosis before the administration of antimalarials to prevent malaria misdiagnosis and drug resistance. $^{10}$

\section{GLOBAL MALARIA CONTROL STRATEGY: THE STORY SO FAR}

World Health Organization report shows a decline in malaria cases by 25 per cent globally and 33 per cent in Africa between 2000 and 2015, with a decrease in both the incidence and death rates by 37 and 60 per cent respectively, a development associated with increased malaria prevention mechanisms and health seeking behaviour in reducing the burden of malaria in pregnancy. Further efforts include the use of insecticide treated net (ITN) and effective case management of malaria and anaemia in pregnant women. ${ }^{1,7,11}$

In Nigeria, a national programme to eliminate malaria was launched in 2015, meanwhile, in 2004 Nigeria adopted World Health Organization's three (3) pronged strategy for combating malaria in pregnancy (MiP), which are: (1) intermittent preventive treatment in pregnancy (IPTp) through the directly observed therapy with Sulphadoxine-Pyrimethamine (SP), (2) distribution and use of insecticide treated net (ITN), and (3) case management of MiP. ${ }^{12}$

\section{INTERNATIONAL COLLABORATION TOWARDS ERADICATION AND CONTROL OF MALARIA IN NIGERIA}

Nigeria became the $17^{\text {th }}$ Presidential Malaria Initiative
(PMI) country in 2010 although, pre-PMI malaria funding in Nigeria was $\$ 18$ million and rose to $\$ 43.6$ million in Fiscal Year (FY) 2011, and was projected at $\$ 43.2$ million in FY 2012. Furthermore, Malaria Action Programme for States (MAPS) a PMI-funded integrated malaria project which was to cover the period 2010 to 2015 was implemented in six (6) states in Nigeria, among them were: Benue, Cross River, Ebonyi, Nasarawa, Oyo and Zamfara. Furthermore, before the support from USAID/PMI, Nigeria received a total of \$280 million from World Bank for the Malaria Booster Programme which supported seven(7) states and some national level activities up until 2009. Also, U.K. Department for International Development (DFID) supported Nigeria with a $\$ 100$ million five-year programme under the Support for Nigeria malaria programme (SuNMaP) in2oo8. Lastly, Global Fund also provided \$500 Million Round 8 Malaria Grant that began in 2009 and expired in 2014. ${ }^{12,13}$

\section{CONCLUSION}

Malaria infection is a major threat to the lives and wellbeing of pregnant women and young children ( under five years of age).

\section{RECOMMENDATIONS}

Stakeholders should ensure that clinical diagnosis must be confirmed by a laboratory parasite-based diagnosis before the administration of antimalarials, and the distribution of insecticide treated nets alongside health education to improve health-seeking behaviour with the aim of preventing malaria infection among pregnant women and young children.

\section{REFERENCES}

1. Goshu Y, Yitayew A. Malaria knowledge and its associated factors among pregnant women attending antenatal clinic in Adis-Zemen Hospital, NorthWestern Ethiopia, 2018. PLoS ONE 2019:14(1):e0210221

2. Omer SA, Idress $\mathrm{K}$, Adam I, Abdelrahim M, Nouredein A, Abdelrazig A, Elhassan M, Sulaiman S. Placental malaria and its effect on pregnancy outcomes Sudanese women from Blue Nile State. Malaria Journal 2017:16(1):374.

3. Fana S, Bunza M, Anka S, Imam A, Nataala S. Prevalence and risk factors associated with malaria infection among pregnant women in a semiurban community of north-western Nigeria .Infectious Diseases of Poverty.2015:4(1):24.

4. Tegegne Y, Asmelash D, Ambachev S, Eshetie S, Addisu A, Zeleke A. The Prevalence of Malaria among 
Pregnant Women in Ethiopia: A Systematic Review and Meta-Analysis. Journal of Parasitology Research. 2019:(1):1-9.

5. Ibeneme G, Ojone M, Nwode I. Prevalence and effect of malaria in pregnancy among antenatal women in Ebonyi State, Nigeria. International Research Journal of Public and Environmental Health 2017:4(8):171-8.

6. Okpua C, Uduituma O. Prevalence of malaria among pregnant women who sleep under insecticide treated nets in Abakaliki: A retrospective study. Journal of Medicine and Medical Sciences.2018:9(2):15-20.

7. Djabanor J, Quansah, Asante D. Effects of malaria in pregnancy on (MiP)on pregnancy development and its outcome : A critical review article info abstract. Journal of Applied Biology and Biotechnology. 2017:5(2):8-16.

8. Dombrowski J, Souza R, Lima F, Bandeira C, Murillo O, Costa D, Peixoto E, Cunha M, Andrade P, Berillacqua E. Association of malaria infection pregnancy and head circumference of newborns in Brazillian Amazon. JAMA Network Open 2019:2(5):e193300.
9. Barboza R, Lima F, Reis A, Murillo O, Peixoto P, Bandeira $\mathrm{C}$, et al. TLR4-mediated placental pathology and pregnancy outcome in experimental malaria. Scientific Reports. 2017:(1):8623.

10. Wogu M, Nduka F. Evaluating malaria prevalence using clinical diagnosis compared with Microscopic and Rapid Diagnostic Tests in a Tertiary Healthcare Facility in Rivers State, Nigeria. Journal of Tropical Medicine. 2018:1:1-4.

11. Malaria Policy Advisory Committee. Malaria in pregnancy: Background Document for Season 4. World Health Organization, Geneva, Switzerland.2015:1-37.

12. USAID. Nigerian malaria in pregnancy: Country profile. USAID.2018

13. United States Embassy in Nigeria. Nigerian malaria fact sheet. United States Embassy in Nigeria. 2011

Source of support: Nil, Conflict of interest: None declared

Cite this article as:

Omang J, Ndep AO, Offiong D, Otu F, Onyejose K. Malaria in

Pregnancy in Nigeria: A literature review. Int Healthc Res J. 2020;3(11):346-348. https://doi.org/10.26440/IHRJ/0311.02315 